Tropical Journal of Pharmaceutical Research June 2017; 16 (6): 1443-1451

ISSN: $1596-5996$ (print); 1596-9827 (electronic)

(C) Pharmacotherapy Group, Faculty of Pharmacy, University of Benin, Benin City, 300001 Nigeria.

All rights reserved.

Available online at http://www.tjpr.org

Review Article

http://dx.doi.org/10.4314/tjpr.v16i6.32

\title{
An overview of the prevalence and distribution of gastrointestinal parasitic infections in post-war Iraq
}

\author{
Noor Abdulhaleem ${ }^{1,2}$, Aliyu Mahmuda ${ }^{1,3}$, Al-Zihiry Khalid Jameel Khadim ${ }^{3}$, \\ Roslaini Abd Majid ${ }^{1}$, Leslie Than Thian Lung ${ }^{1}$, Wan Omar Abdullah ${ }^{5}$ and \\ Zasmy Unyah ${ }^{1 *}$ \\ ${ }^{1}$ Department of Medical Microbiology and Parasitology, Faculty of Medicine and Health Sciences, Universiti Putra Malaysia, \\ 43400 UPM Serdang, Malaysia, ${ }^{2}$ Department of Biology, College of Science, University of Anbar, Anbar, Iraq, ${ }^{3}$ Department of \\ Parasitology and Entomology, Faculty of Veterinary Medicine, Usmanu Danfodiyo University, Sokoto, Nigeria, ${ }^{4}$ Department of \\ Microbiology, College of Medicine, University of Thi-Qar, Thi-Qar, Iraq, ${ }^{5}$ Department of Medical Sciences, Faculty of Medicine \\ and Health Sciences, Islamic Sciences University of Malaysia, Kuala Lumpur, Malaysia
}

*For correspondence: Email: ngah@upm.edu.my; Tel: +60132213516

Sent for review: 10 January 2017

Revised accepted: 17 May 2017

\begin{abstract}
Many modern-day diagnostic tests for parasitic diseases rely on conventional labour-intensive technologies such as serology and microscopy. Although major advances have been recorded in the diagnosis of infectious diseases in humans, parasitic diseases continue to present challenges, particularly in resource-poor countries, and this is mainly attributable to war and famine. Factors such as poverty, deteriorated health facilities and destruction of infrastructure are the consequence of the lack of suitable sanitary practices and proper hygiene, especially in refugee camps, that adversely promote infectious diseases to migrants, particularly among vulnerable children. Generally, the gastrointestinal tract is the predilection site for most helminths and protozoa. They are therefore regarded as a serious public-health problem, as they cause malabsorption, malnutrition and blood loss, leading to anaemia or even death. In addition to their health effects, parasitic infections cause physical and mental impairment in children, retard their educational achievements and hinder economic development.
\end{abstract}

Keywords: Prevalence, Parasitic diseases, Intestinal parasite, Food-borne, Water-borne, Pathogens, Post-war, Iraq

Tropical Journal of Pharmaceutical Research is indexed by Science Citation Index (SciSearch), Scopus, International Pharmaceutical Abstract, Chemical Abstracts, Embase, Index Copernicus, EBSCO, African Index Medicus, JournalSeek, Journal Citation Reports/Science Edition, Directory of Open Access Journals (DOAJ), African Journal Online, Bioline International, Open-J-Gate and Pharmacy Abstracts

\section{INTRODUCTION}

Intestinal parasites constitute a significant public health problem, particularly in tropical and subtropical countries where adequate water and sanitation are lacking [1]. It is estimated that about 3.5 billion people are affected in developing countries, the majority of which are children (450 million, nearly $30 \%$ ) [2]. In these developing countries, over $80 \%$ of all deaths are attributed to infectious and parasitic diseases [3]. The high prevalence recorded in these countries is closely associated with poverty and deteriorated health infrastructure, lack of hygiene and good sanitary practices, as well as the possible introduction of infections through refugee camps and migration due to war and famine [4]. Despite efforts in improving hygiene and sanitation, cases of parasitic infection are still on the rise, particularly among school-aged children in war-torn countries [5].

The prevalence of intestinal parasitic diseases is an indication of a deteriorated environment. As a 
consequence of war and insecurity, a large number of people are displaced in refugee camps. This has led to deterioration in cleanliness, which is known to predispose to parasitic infections, particularly with primitive standards of living and personal habits of cleanliness [6]. The most common parasitic infections in refugee camps in the context of Iraq include helminth infections such as ascariasis, trichuriasis, teaniasis, enterobiasis, hymenolepiasis, hookworm infections and protozoan diseases such as amoebiasis, giardiasis, balantidiasis, microsporidiosis, cryptosporidiosis, and leishmaniasis. Parasitic infections have also been documented as capable of causing severe complications, especially in immunosuppressed conditions, due to malnutrition in children among native communities in Iraq [7].

Interestingly, among the major clinical signs of gastrointestinal diseases is diarrhoea. This remains the second leading cause of death among children below five years of age globally, and nearly about 1.5 million annual child deaths have been suggested to be caused by diarrhoea, as it kills more young children than AIDS, malaria and measles combined [8]. Parasitic diseases are prevalent in developing countries, and are considered among the most common diseases affecting third world countries. The prevalence of disease in Iraq varies from region to region. The variation in distribution of disease in the country highly depends on personal and community hygiene, as well as on prevailing climatic conditions [5]. The rate of regional prevalence, as indicated by the Communicable Disease Report Control Centre, Iraq [8] has revealed Basra with the highest prevalence (59.98\%); followed by Sulaimani (26.28 \%); Najaf (24.89 $\%)$; Duhok (20.10\%); Nassriyah (12.02 \%) and Anbar $(7.08 \%)$. Similarly, Basra had the highest case of infection of Giardia lamblia (39.28 \%), while the least infected city was Tikirit $(2.95 \%)$.

\section{SOURCES, PREVALENCE AND MODE OF TRANSMISSION OF GASTROIN- TESTINAL PARASITIC DISEASES}

There is no doubt that gastrointestinal parasitic infections are acquired through various sources and routes. This is because several factors form the bedrock for their development and/or favours their survival, and as well serves as a carrier for the transmission of these pathogens. Among the most efficient modes of transmitting these organisms is through contaminated water and food, which are known to be the major routes for GIT parasites, in addition to those usually transmitted by contact. With the exception of a few, almost all gastrointestinal helminths and protozoan infections are acquired by ingestion of infective stages, either in food or drinking water. This disease transmission mode has given foodborne and water-borne infectious agents a significant contribution in enhancing the epidemiology of most GIT parasites.

\section{Water-borne parasitic diseases}

The primary source of contamination of water bodies is from stool of infected humans and animals. A number of investigations have been conducted in different regions across Iraq to determine the level of contamination of drinking water with parasites of significant public health implication. In a seven-month study conducted in the marsh regions of south Basrah, Iraq (November, 2012 to May, 2013 [9], among the total 425 water samples collected, 155 (36.4\%) were contaminated with intestinal parasites, as revealed by direct, sedimentation and floatation methods. Entamoeba histolytica is the most prevalent parasite detected, amounting to $8 \%$ of the total positive samples. Giardia lamblia accounted to $7.2 \%$ while the remaining $84.8 \%$ represents other types of parasites, but in lower rates. The study also evaluated the factors favouring the growth and persistence of these parasites, as well as environmental factors. The villages of the marsh land had the highest prevalence, which was attributed to poor environmental and personnel hygiene, as well as a deteriorated water supply infrastructure [9]. The lack of filtration, rottenness of water distributing pipes and warm climate in the Basrah province are also other factors [9].

Similarly, in a related study conducted to determine the prevalence of intestinal parasites in children less than five years of age in the Hilla, Babylon Province, 138 of them (39.5\%) were positive for intestinal parasitic infection, among 349 stool samples collected [10]. It is also known that children under five years of age are prone to contracting parasitic infections, due to their poorly developed immune systems [11]. They are also more predisposed as a consequence of direct contact with faecal contaminated soil. The most common parasite isolated in this study was Entamoeba histolytica (13 \%); while Giardia lamblia, Hymenolepis nana and Enterobius vermicularis had a 7.2, 6.0 and $5.2 \%$ prevalence, respectively.

Furthermore, in 2014, in Wasit, Giardia lamblia was the predominantly isolated parasite, with a prevalence of $41.8 \%$, representing 94 samples among 225 children sampled. Contrastingly, this study indicates that female children had a slightly 
higher prevalence rate $(21.8 \%)$ compared to males $(20 \%)$. According to age, the highest percentage of infection, $17.3 \%$, was found in the 4 to 6 year old age group; while $16.4 \%$ was found in day care centres, and $10.2 \%$ was found in primary school-aged students. A significant association was found between Giardia lamblia infection and water contamination. About $31.6 \%$ of the inhabitants use storage water, while only $1.3 \%$ use sterile bottled containers [12].

A hospital survey was conducted from October, 2003 to May, 2004, among patients in Marjan Hospital in Hilla City. A total of 243 faecal samples (128 male and 115 female) was collected and examined [13]. Analysis of the samples revealed that five different pathogenic intestinal parasites comprising two protozoans (Entamoeba histolytica $27.9 \%$, Giardia lamblia $13.9 \%$ ) and three helminths (Hymenolepis nana $5.3 \%$, Enterobius vermicularis $2.4 \%$ and Ascaris lumbricoides $2.8 \%$ ) parasites were responsible for various diseases recorded among the sampled patients. A negative correlation was demonstrated between the percentage incidence of infection, with the intestinal pathogenic parasites and gender of the patients. Statistically significant differences were observed among the overall incidence and the quality of the drinking water consumed. Dieng [14] reported that contaminated water is a serious public health problem globally, and this usually results in infection following ingestion (drinking), or direct contact with water contaminated by infected faecal material. In this study, a higher incidence was recorded among patients using river water $(80.8 \%)$, while those drinking tap water had lower cases (43.8\%).

Rasha et al [15] recently conducted a study to determine parasitic contamination in the River of Al-Kufa, which is the primary source of water for the Al-Najaf province. As a result of the rapid population growth, modern agricultural practices and urbanization, and municipal and agricultural wastes, are increasingly indiscriminately being dumped in the river. Samples were collected from July 2012 to February 2013, at approximately bi-monthly intervals. The most prominent source of pollution to the river was from the sewage, drainage, abattoir waste and effluents discharged directly into the river. Enteric protozoan parasites were Giardia lamblia, Cryptosporidium parvum, and Entamoeba histolytica, Balantidium coli, and this tends to reveal the possible risk of contracting these infections, particularly when hygienic standards are poor, such as in refugee camps. Helminths, like Ascaris lumbricoides, Ancylostoma duodenale, Trichuris trichuria, Taenia saginata, and Fasiola hepatica, were highly prevalent, and these are known to be transmitted between humans and livestock. In the same vain, the distribution of intestinal parasites in drinking water in some parts of Baghdad was investigated by Hadi and Faraj [16]. A total of 180 tap water and 90 sewage water samples from residences in Al-Dura, Hi-Al- Maalf, Hi-Al-Jehad, Al-Shabab, and Al-Baya'a were collected in Baghdad city. About 17.2 and $60 \%$ contamination was recorded for tap and sewage water, respectively, using a sedimentation technique.

\section{Food-borne parasitic diseases}

Outbreaks of human infections following the consumption of food and vegetables are currently reported to be on the rise. The predisposing factors to these include: changes in agricultural and processing practices, overcrowding in refugee camps, changing feeding habits to consumption of raw or minimally-processed foods, fruits and vegetables, increase in international trade and tourism, as well as increase in the number of immuno-compromised consumers as a result of war, poverty or famine. The increase in cases of food borne parasitic infections is potentiated by the gross lack of efficacy of sanitizers in destroying pathogens on raw food, fruits and vegetables, as well as the lack of efficient hygienic food processing practices. Leafy vegetables constitute an important component of a healthy diet in many countries, including Iraq. They are mainly eaten raw, thereby increasing the likelihood of food borne parasitic infections. Epidemiological surveys have shown that the use of waste water to irrigate vegetables that are eaten raw without proper washing, accounts for the majority of foodborne parasitic infections $[17,18]$.

The role of domestic and wild dogs in the spread of parasitic diseases was highlighted by studies aiming to evaluate the level of contamination of leafy vegetables sold at various markets in Erbil City [19]. The study revealed that the eggs of Echinococcus granulosus were found in three types of vegetables (celery, rocket and parsley), with the highest prevalence rate being $22.4 \%$. The result of the survey shows that, among 72 samples of six different types of leafy vegetables (i.e. celery, rocket, parsley, leek, dill and cress), weighted between 400-500 gm examined, 49 $(68.05 \%)$ were found to be positive for parasitic eggs, cysts and larvae. The $12.2 \%$ contamination with Toxocara eggs discovered is disturbingly high, and may be attributed to the contamination of these vegetables with dog or cat faeces, which may serve as source of 
infection to man and susceptible domestic animal species. The study is in agreement with a later study [20] conducted in the Alqalamoun region of Iraq, and has also confirmed similarity with another previous studies [21] in Sulaimani city, Iraq.

It is also worthy to note that the development of a severe syndrome called parasitic gastro-enteritis (PGE) is due to continued effects of a set of GIT nematodes. It constitutes a serious health threat and economic burden by gravely affecting livestock productivity, due to the associated morbidity, mortality, costs of treatment and institution of control measures. A survey on the prevalence of gastrointestinal tract (GIT) parasites in goats was conducted in and around the Sulaimani province in the Kurdistan Region of Iraq [22]. Between September, 2009 and May, 2010, a total of 316 faecal samples were collected from local goats, and in some selected areas of Sulaimani province reported for parasitological examinations (Sulamani Center, Arbat, Aghgeler and Said Sadeq).

The study revealed that goats in the Sulaimani province are commonly infected with a variety of gastrointestinal parasite species, with an overall prevalence of $44.9 \%$. The implication of indiscriminate drenching of livestock by farmers was also highlighted as being a cause for the persistence of certain gastrointestinal parasite eggs in large quantities, and the possibility of developing resistance to these agents in the near future.

\section{Types of gastrointestinal parasites involved}

In Iraq, many of the parasitic infections are caused from nematodes, cestodes, trematodes and the luminal protozoan parasites that inhabit the gastrointestinal tracts of mammals, including humans and animals. The most common parasites reported from several studies conducted include: Entamoeba histolytica, Giardia lamblia, Balantidium coli, Leshmania spp, Microspora spp, Hymenolepis nana, Cryptosporidium parvum, Ancylostoma braziliensis, Strongyloides stercoralis, Trichuris trichuria, Teania saginata, Ascaris lumbricoides and Enterobius vermicularis [23-26]. The increase in the prevalence of these parasites is a clear indication of environmental contamination with infective stages, which are usually the result of poor sanitation. Infection with any of the above listed parasites is solely moderated by poor hygiene and the subsequent intake of infective stages, mainly through ingestion, and by the cutaneous route for Strongyloides stercoralis and Ancylostoma spp.

\section{Amoebiasis}

Entamoeba histolytica has been reported in most parts of the world. It is more prevalent in tropical and subtropical regions, while in cooler temperate climates, it is mostly found in unsanitary conditions. Amoebic dysentery is widely spread in areas characterized by poor health and livelihood conditions, especially in poor-resource environments [27]. Predominantly, the disease is also endemic in some African, Asian and South American countries. The estimated global incidence is at about 500 million persons annually, associated with about 100,000 deaths. The disease manifests with different clinical presentation that vary from region to region. In the majority of cases, the disease is asymptomatic, but $10 \%$ of infected persons show signs of systemic illness [27]. Amoebic colitis, for instance, is more common in Egypt, while liver abscess is more commonly seen in South Africa; with a severity depending on virulence of the infecting strain, host susceptibility and immune status, as well as a concurrent infection with other intestinal parasites [28].

The treatment of water by chlorination does not destroy $E$. histolytica cyst, and infective stages can often be easily transmitted, even in hygienic settings. Resistance strains have been reported due to drug resistance exhibited by immunocompetent individuals who eventually become carriers [29]. In a related study, AlKubaisy et al [24] reported $22 \%$ parasitic diarrhoea in children in Baghdad among 2,033 cases. The most prevalent parasite was $E$. histolytica, with an estimated prevalence of 23.44 $\%$. The study also indicated that the infection is higher in males $(22.37 \%)$ compared to females $(21.56 \%)$. Similarly, the study is in line with that by Waqar et al. [30], who investigated intestinal parasitic diarrhoea cases among children in Baghdad, Iraq.

Entamoeba histolytica has also been reported to be the most prevalent parasite in the Babylon province $(36.7 \%)$ and rural villages in the Basrah marshes region. In the Basra region, the disease was reported to be higher among pre-school children which were attributed to drinking contaminated milk and water, as well as poor hygiene [25]. In the Al-Doullab village of the Babylon province, samples were collected from patients in a primary health centre. The community is known for agricultural production and animal breeding (mostly cattle, sheep, goats and poultry). E. histolytica cysts had an overall prevalence of $60.15 \%(60.9 \%$ male and $58.7 \%$ 
female) [31]. Diarrhoeal diseases are a major cause of child mortality, particularly in low and middle-income populations [32]. The health and living conditions of the children in Iraq deteriorated during the invasion, with increased mortality among children [33]. In the developing world, an upsurge in immune-mediated gut disorders, malnutrition and deterioration of health care facilities, has led to an increase in cases of child diarrhoea with high morbidity and mortality. The increasing cases of $E$. histolytica infections in children are attributed to poor hygienic practices and lack of adequate treatment of drinking water due to war and famine.

Hospital-based studies conducted in AlMahmoudiya, Baghdad province and Shatrah district, Thi-Qar governorate [34] indicate that the most prevalent intestinal parasitic infection found among hospitalized children is $E$. histolytica, with an overall prevalence of 57.8 and $43.1 \%$, respectively. $E$. histolytica incidences were reported to be $29.2 \%$ in Shatra district, and $41 \%$ in Al-Mahmoudia. A possible reason for these results could be attributed to the widespread direct transmission of this parasite through contaminated water and food, as well as the very poor standards of hygiene and sanitation. The lack of treatment of sewage before disposal into rivers and lakes could also predispose communities using these water bodies for household activities and irrigation to infection.

Basima [35] also studied the prevalence of intestinal parasites among children attending AlDaura Health Centre, Baghdad. Specimens were chosen randomly and examined, and $160(45.7$ $\%)$ were found to be infected, $140(87.5 \%)$ harboured one parasite, while 20 (12.5\%) had multiple infections. E. histolytica infections (11.25 $\%$ were mostly recorded to be prevalent in school children in the age range of 5-14 years. In another report, 252 primary school boys and girls between the ages of 6-11 were studied in ThiQar to determine parasitic infestation. The general prevalence observed was $46.4 \%$. Various species of intestinal parasites were detected, with $E$. histolytica reported in $14 \%$ of total infections. This further testifies the need for measures to control the transmission cycle of this disease among children. A similar study by Ibrahim [36] was conducted on the prevalence of E. histolytica and G. lamblia in children in Kadhmiyah Hospital. Among the 1,520 stool samples collected from children (1 month to 12 years of age), $E$. histolytica infection was reported to be $9.80 \%$. The study revealed a direct correlation between different age groups and the disease.
As mentioned previously, infection with $E$. histolytica is more common among children under five years of age, particularly in school aged children. This is because the children are exposed to sand and water that has been contaminated by human stool containing the cysts of E. histolytica. Another study has additionally reported a high prevalence of the disease among children within this age range [37]. He studied the prevalence of viral causes of diarrhoea in children less than 5 years of age in the Baghdad province. In his study, a total of 250 samples comprising 40 dysenteric stool specimens with bloody diarrhoea were collected; the most common pathogen isolated was $E$. histolytica. In another study to determine the prevalence of $E$. histolytica and $G$. lamblia among diarrhoeal patients in Samarra city, a high prevalence of these parasitic infections was recorded during the winter season. The study also showed a statistically significant difference between inhabitants of rural and urban communities, as well as between male and female children in the study area.

Reports on the prevalence of E. histolytica in regions of Iraq are also in agreement with other studies conducted worldwide. This includes reports from Afghanistan [38] within the Middle Eastern region, which indicated $E$. histolytica as the predominantly detected intestinal parasite among school children (with a $17.4 \%$ prevalence). The prevalence of $E$. histolytica among primary school children was also studied in Akure, Ondo State, Nigeria, a tropical region with relatively high rainfall [39]. A prevalence rate of $67.63 \%$ was reported, with females having a slightly higher rate $(68.28 \%)$ than their male counterparts $(66.92 \%)$. The study similarly observed that pupils using stream water had the highest infection (94.29\%), and that the lack of hand washing before eating was one of the major predisposing factors in enhancing disease transmission, in addition to other socio-economic factors and bad infrastructure observed in most of the district villages.

\section{Giardiasis}

The causative agent of giardiasis is a flagellate protozoan parasite that affects people on a global scale. Although it is more prevalent in areas with poor sanitary conditions, the disease is common among developing countries, including Iraq [40]. The overall prevalence of $G$. lamblia in industrialized countries ranges from 2 $7 \%$, while it is as high as $20-60 \%$ in developing countries [41]. The majority of cases are asymptomatic, but occasionally, some cases with diarrhoea and intestinal irritation which 
account for the problem of malnutrition and nutritional deficiency are also associated with children [42]. The mode of transmission of the disease is by ingestion of contaminated food and water, or via direct person-to-person contact. It is particularly common among primary school children, especially those that are often in direct contact with contaminated water. Several surveys of intestinal parasitic infection in Iraq have indicated that the intestinal protozoan parasite is the most common infection in Iraq [43]. The disease is often overlooked during clinical investigations in health institutions in the country [44].

Giardia lamblia is also recognized as an important public health concern among several communities in Iraq. Studies have established a close relationship between infection and poor living conditions. In a study conducted in Thi-Qar, Southern Iraq, among children with acute diarrhoea, a prevalence of $23.7 \%$ was reported. The disease, Giardiasis was shown to predominantly affect children between the ages of 2 - 4 years [45]. The study also observed an inclination of the disease in rural areas, children raised by low level educated mothers, and living in large families with many children. Similar work has shown that there was a significant association between giardiasis and age, with most infections recorded in 2 - 6 year old school children and day care centres [12]. The disease is known to be common among children due to their poorly developed immune systems, and frequent contact with the pathogen while playing in contaminated soil or water. Moreover, the prevalence of $G$. lamblia varies significantly between different studies conducted in various Iraqi communities, including refugee camps. Some of the studies illustrated higher prevalence levels in the rural areas with poor levels of drinking water and sanitation [45-47]; while others showed a higher prevalence among urban communities $[12,48]$.

Prevalence as high as $41.8 \%$ was reported among children in Wasit governorate [12], while prevalence as low as $10.31 \%$ was reported among displaced people in the Kirkuk province [49]. This report is in contrast with several other reports in Iran [50], Yemen [51], Egypt [52] and Colombia [53]. This is because higher prevalence is expected in war-torn countries with poor living conditions. Perhaps the disparity may be explained by the number of samples collected, and the age range considered for sampling. Salman et al [49] sampled those in the age range of 1-60 years, while most studies sampled mostly 2-6 years-old school children. A similar study was reported in Syria [54]. Giardia lamblia cysts were found to be the most prevalent parasite (13.13\%), followed by Entamoeba histolytica cysts (8.75 \%), Enterobius vermicularis eggs (5.83\%), and Ascaris lumbricoides eggs (3.64 \%).

The highest contaminated vegetable detected was in lettuce and parsley (32.56\%) and the lowest was radish (4.65\%) found in refugee camps in Iraq. It is well known that raw vegetables are viewed as an important source of intestinal parasitic infections, especially in places where organic manure is used, and fruit is not properly washed and processed. Giardia continues to pose health threats such as dehydration among children. The disease seems to thrive in terms of its ubiquity, and is consequently becoming an important disease with great interest among researchers. The disease is viewed as an emerging problem in a variety of epidemiological settings, commonly in refugee camps and communities ravaged by war and break down of public health infrastructure. It is also emerging as a parasitic infection in children, particularly those attending day cares or living in large family settings; as well as in domestic animals throughout the world.

\section{Helminthiasis}

In third world countries, including Iraq, the majority of helminths infections are associated with poor sanitary facilities, indiscriminate disposal of human waste, inadequacy and lack of quality drinking water. It is also potentiated by poverty and low socioeconomic status [55]. Over 2 billion people are said to be infected with helminths, the majority of which reside in developing countries [56]. Humans at the highest risk of infection with helminths include immune suppressed pregnant women and pre-school and school-aged children [57]. Helminths infections are known to cause reduced food conversion and subsequently retarded growth, diminished physical fitness and slow cognitive and intellectual development $[56,57]$. This prominent disease is of great public health significance in Iraq and other parts in the Asian and African continents, especially in poorly developed countries.

A retrospective study conducted from January to December, 2013 using available surveillance data on gastrointestinal nematodes and cestodes and their relationship with age, sex and region with the disease in Iraq [58] revealed an overall prevalence of $1.39 \%$. The predominant helminth found in the study was Enterobius vermicularis. Although male individuals had higher helminth infections, there was no statistically significant 
association between the disease and sex. The infection was found to be more common among children. This is attributed to their frequent exposure to conditions that favour the transmission of the infective stages of most of the helminths, especially the soil-transmitted types. Another study demonstrated that the hand washing habit before eating is not commonly practiced among children in war-torn countries [59]. This finding is consistent with the result of Arinola and Fawole [60], who observed that the prevalence and intensity of some intestinal helminths were predominant in the same age group in Iraq.

The overall prevalence reported in Iraq was found to be higher than reports by other Asian countries, and this was attributed to seasonal diversity, public health services and personal hygiene. The majority of ascariasis, ancylostomiasis, trichuriasis, strongyloidiasis, and enterobiasis cases were found mostly in children; while hymenolepiasis and taeniasis were reported mostly in adults. An apparent seasonal tendency was recognized in the monthly prevalence of the helmints infection in Iraq (from January to December 2013). The most common helminth infection in this survey was enterobiasis, followed by hymenolepiasis. Enterobiasis and hymenolepiasis are cosmopolitan in distribution, and are more common in warm climates. They have a global distribution and are transmitted directly from person to person, and by autoinfection [61].

\section{CONCLUSION}

The prevalence of intestinal parasites is an increasing global public health concern, especially in war-torn countries like Iraq. Social disturbance and migration of the population in these countries have becomes the important loci for the transmission of infectious diseases. Children tend to harbour the greatest number of intestinal parasitic infections, resulting in stunted growth and diminished physical fitness, as well as impaired memory and cognition. These health challenges combine to lead to impairment of childhood educational performance and predispose children to increased risk of nutritional anaemia, malnutrition, growth deficits and physical weakness, especially those in refugee camps. The high prevalence rates of gastrointestinal parasites reported by several authors in different Iraqi communities and provinces have merited a spotlight as an important problem. Health education should be increased to raise awareness of the society about such an important health problem inherent in the country.

\section{DECLARATIONS}

\section{Acknowledgement}

This work was supported by Universiti Putra Malaysia, Malaysia.

\section{Conflict of Interest}

No conflict of interest associated with this work.

\section{Contribution of Authors}

The authors declare that this work was done by the authors named in this article and all liabilities pertaining to claims relating to the content of this article will be borne by them.

\section{Open Access}

This is an Open Access article that uses a funding model which does not charge readers or their institutions for access and distributed under the terms of the Creative Commons Attribution License (http://creativecommons.org/licenses/by/ 4.0) and the Budapest Open Access Initiative (http://www.budapestopenaccessinitiative.org/rea d), which permit unrestricted use, distribution, and reproduction in any medium, provided the original work is properly credited.

\section{REFERENCES}

1. Damen JG, Luka J, Biwan El, Lugos M. Prevalence of Intestinal Parasites among Pupils in Rural North Eastern, Nigeria. Nig Med J 2011; 52(1): 4-6.

2. Teklu W, Tsegaye T, Belete S, Takele T. Prevalence of intestinal parasitic infections among highland and lowland dwellers in Gamo area, South Ethiopia. BMC Public Health 2013; (13): 151.

3. Faten $A A$. Is intestinal parasite infection still a public health concern among Saudi children? Saudi Med J 2008; 29(11): 1630-1635.

4. Rashid MK, Joshi M, Joshi HS, Fatemi K. Prevalence of Intestinal Parasites among School Going Children in Bareilly District. NJIRM 2011; 2(1): 2230-9969.

5. Sehgal R, Gogulamudi VR, Jaco JV, Atluri V. Prevalence of intestinal parasitic infections among school children and pregnant women in a low socio-economic area, Chandigarh, North India. RIF 2010; 1(2): 100-103.

6. Mamoun MM, Abubakr IA, El-Muntasir TS. Frequency of intestinal parasitic infections among displaced children in Kassala Town. Khartoum Med J 2009; 2(1): 175-177.

7. Bdewi AM. Prevalence of intestinal parasites among patients attending some of Baghdad hospitals. J Pure Sci Al-Anbar Uni 2009; 3(2): 1-11. 
8. United Nations International Children's Emergency Fund. Annual Report of Communicable Disease Report Control Centre, Iraq, 1990.

9. Jarallah $H$. Intestinal parasitic infections among rural villages in Basrah marshes regions. Journal of Basrah Res Sciences 2012; 38(2): 40-43.

10. AL-Khafaji YA, AL-Jiboury HJ. Detection of Rotavirus in diarrhea stool samples of children with acute gastroenteritis in Babylon governorate, Iraq, Intern Res Journ Microb 2013; 4(3): 84-88.

11. Rao V, Sugunan A, Murhekar M, Sehgal S. Malnutrition and high childhood mortality among the Onge tribe of the Andaman and Nicobar Islands. Pub Heal Nutr 2006; 9:19-25.

12. Muslim. The prevalence of giardia lamblia among infants and young children in Wasit governorate, Iraq. Sci Med 2014; 7 (4), 181-189.

13. Al-Morshidy K. Prevalence of intestinal pathogenic parasites infections in Hilla city, Babylon province, Iraq J. Babylon Univ. Pur. Appl. Sci 2007; 14 (1), 179-185.

14. Dieng $Y$. Intestinal parasitosis in the inhabitants of a suburban zone in which the groundwater is polluted by nitrates of fecal origin (Yeumbeul, Senegal)]. Sante 1999; 9(6): 351-356.

15. Rasha ANA, Sinan QK, Ammar AR. Investigation of parasitic contamination in Kufa river water-Al-Najaf province. Magazin of Al-Kufa Univer Biol 2014; 6 (2),

16. Hadi AM, Faraj AA. Distribution of intestinal parasites in drinking water in some regions in Baghdad. Al-Qadisiya J. Vet. Med. Sci 2008; 7(2): 33-36.

17. Damen JG, Banwat EB, Egah DZ, Allanana JA. Parasitic contamination of vegetables in Jos, Nigeria," Annals Afri Med 2007; 6, (3), 115-118.

18. Mona AM, Emmanuel ES, Arwa HE, Ali MME, Awad AN. Parasitic contamination of fresh vegetables sold at central markets in Khartoum state, Sudan Ann Clin Microbiol Antimicrob 2016; 15:17.

19. Louis AS, Khader NN. Prevalence of parasitic Stages in Six Leafy Vegetables in Markets of Erbil City, Kurdistan Region-Iraq. Zanco Jour of Pure App/ Sci 2014; 26(2),

20. Alhabbal AT. The prevalence of parasitic contamination on common cold vegetables in Alqalamoun region. Int $J$ Pharm Sci Rev Res 2015; 30(1): 94-97.

21. Shahnaz AA, Hersh AA. Prevalence of human intestinal parasites in selected vegetables in Sulaimani city. JSMC 2010; 3, (1),

22. Nassrullah AJ. Prevalence of Gastrointestinal parasites in sheep in Sulaimani province. Al-Anbar Jour Vet Sci 2011; 4 (2), 34-36.

23. Abdulkadir AA, Bernawi SM, Omar SEO. Prevalence of Giardia lamblia in Humans Visited Central Laboratory of Sebha Province. Intern Jour Engin Sci and Innov Techn (IJESIT), 2013; 2 (3): 2319-5967.

24. AL-Kubaisy W, AL-Talib H, Al-khateeb A, Shanshal MM. Intestinal Parasitic Diarrhea among Children in Baghdad, Iraq. Trop Biomed 2014; 31(3): 499-506.

25. Al-Saad RK, Al-Emarah GY. Epidemiological Comparative Study of Giardia lamblia Between Human and Cow in Basrah, Iraq. Intern Jour Innov and Appl Stud 2014; 7 (3), 843-848.

26. Abdul- Kareem MA, Huda A, Nadia HM. Diagnosis of Giardia lamblia by Detection of Parasite- Anti-Giardia Antibodies in Children. Intern Jour of Adv Res 2015; 3 (2): 90-94.

27. Ravdin Jl, Stauffer WM. Entamoeba histolytica (amebiasis). In G. L. Mandell, J. E. Bennett \& R. Dolin (Eds.), Mandell, Douglas and Bennett's Principles and Practices of Infectious Diseases, 2005; (6th ed., pp. 3097-3111). Philadelphia, PA: Churchill Livingstone.

28. Stanley SJ. Amoebiasis. Lancet 2003; 361: 1025-1034.

29. Hawker J, Begg N, Blair I, Reintjes R, Weinberge J. Communicable disease control handbook, 2005; Blackwell Science Publishers, Oxford, England.

30. Waqar A, Hassanain A, Alyaa A, Mohammad MS. Intestinal Parasitic Diarrhea among Children in Baghdad - Iraq Trop Biomed 2014; 31(3): 499-506.

31. Ahmed KA, Al- Hamairy, Ahmed MAA, Abbas HMA. Prevalence of parasitic infection and relationship with anaemia in Al-doullab village, Babylon province, Iraq. Egypt Jour Exp Biol 2013; 9(2): 231-236.

32. Black RE, Morris SS, Bryce J. Where and why are 10 million children dying every year? Lancet 2003; (361): 2226-34.

33. Blacker J, Jones G, Ali MM. Annual mortality rates and excess deaths of children under five in Iraq, 1991-98. Popu Stud (Camb) 2003; 57:217-26.

34. Hadi AM, Faraj AA. Distribution of intestinal parasites in drinking water in some regions in Baghdad. Al-Qadisiya J. Vet. Med. Sci 2008; 7(2): 33-36.

35. Basima AS. Study on the Prevalence of Intestinal Parasites Among Children Attending Al-Daura Health Centre-Baghdad. Sci. J. Nursing / Baghdad 2005; 18 (1):

36. Ibrahim AQ. Prevalence of Entamoeba histolytica and Giardia lamblia in Children in Kadhmiyah Hospital. The Iraqi J. Vet. Med 2012; 36 (1):32-36.

37. Hussein RA, Shaker MJ, Majeed HA. Prevalence of intestinal parasitic infections among children in Baghdad city. J Essent Educ Coll 2011; 71: 139- 147.

38. Korzeniewski K, Augustynowicz A, Smoleń A, Lass A. Epidemiology of intestinal parasitic infections in school children in Ghazni Province, eastern Afghanistan. Pak J Med Sci 2015; 31(6):1421-1425.

39. Simon-Oke IA, Ogunleye E. Prevalence of Entamoeba histolytica among primary school children in Akure, Ondo State, Nigeria. Jour of Pub Heal and Epidem 2015; 7 (11): 346-351.

40. El-safi SH, Al-Magati TN, Hussien MI, Adam AM, AbuHassan MM, Al-Zahrani EM. Comparison of microscopy, rapid immunoassay, and molecular techniques for the detection of Giardia lamblia and Cryptosporidium parvum. Parasitol Res 2013; 112: 1641-1646.

41. Thompson RCA, Lymbery AJ, Meloni BP. Genetic variation in Giardia, Kunstler 1882: taxonomic and epidemiological significance. Protozo Abstr 1990; 14:128. 
42. Dubey R, Molan AL, Farag AM et al. Intestinal giardiasis: an unusual cause for hypoproteinemia. Indian Jour Gastroenterol 2000; 19(1): 365-73.

43. Abd-Alzahra E, Shani WS, Al-Malak MK. Local and systemic immune responses in rats infected with Giardia lamblia. Med J. Baseah Univ 2012; 30 (1): 60-72.

44. Salman YJ, Salih LA. Detection of some microbial infectious agents among children aging below 2 years in Kirkuk city. J. Kirkuk Med. Coll 2013; 1: 53-6.

45. Hussein TK. "Prevalence And Related Risk Factors for Giardia lamblia Infection Among Children with Acute Diarrhea In Thi-Qar, Southern Iraq". Thi-Qar Med Jour (TQMJ), 2010; 4(4); 68-74.

46. Ali JK. Prevalence of Entamoeba histolytica and Giardia lamblia parasites among patients attending Al-Emam All hospital in Al-Mashrooh provice, Babylon. Kufa Jour for Vet Med Sci 2015; 6 (1): 30-34.

47. Turki NM, Muhammed OM, Yassir DK. Iraqi Genotyping of Giardia lambila $(A, B, E, F)$ in Human Stool In $A L$ Muthanna Province-Iraq. Intern Jour of Advanc Res 2015; 3(10): 757 - 771.

48. Saad AA, Ahmed AA, Eltigani OO, Latifa AA, Abdulsalam $Q A$, Faiz $A A$. Pattern of parasitic infections as public health problem among school children: A comparative study between rural and urban areas. Jour Taibah Unive Med Sci 2015; 11(1): 13-18.

49. Salman YJ. Detection of Blastocystis hominis among peoples in Kirkuk Province using ELISA and direct microscopy. Int. J. Curr. Microbiol. Appl. Sci. 2015; 4(10): 686-695.

50. Taherkhani H, Shariati S, Abdolahi N, Roshandel G. Clinical Manifestations of Giardiasis in Iran. J. Clin Diagn Res; 2009; 3:1416-1418.

51. Alyousefi N, Mahdy M, Xiao L, Mahmud R, Lim Y. Molecular characterization of Giardia duodenalis in Yemen. Exp Parasitol 2013; 134(2): 141-147.
52. Yassin M, Shubir M, Al-Hindi A, JadAllah S. Prevalence of intestinal parasites among children in Geza district. J. Egy. Sco. Parasitol 2000; 2(29): 365-373.

53. Jorge HBG, Gisela MGM, Dayvin GP, Daniel CAA, Martha CAU. Giardia intestinalis and nutritional status in children participating in the complementary nutrition program, Antioquia, Colombia, May to October 2006. Rev. Instan. Med. Trop. S. Paulo 2009; 51(3): 501-506.

54. Alhabbal AT. The prevalence of parasitic contamination on common cold vegetables in Alqalamoun region. Int $J$ Pharm Sci Rev Res 2015; 30(1): 94-97.

55. Ragunathan L, Kalivaradhan SK, Ramadass S, Nagaraj $M$, Ramesh K. Helminthic infections in school children in Puducherry, South India. J Microbiol Immunol Infect 2010; 43: 228-232.

56. Jogfdujpot $F$, Hotez PJ, Brindley PJ, Bethony JM, King $\mathrm{CH}$, Pearce EJ, Jacobson J. Helminth infections: the great neglected tropical diseases. Africa (Lond.), 2008; 118:1311-21.

57. Bethony J, Brooker S, Albonico M, Geiger SM, Loukas A, Diemert D, Hotez PJ. Soil-transmitted helminth infections: ascariasis, trichuriasis, and hookworm. Lancet 2006; 367:1521-32.

58. Ihsan MA, Harith SA, Hussain SA. The prevalence of some gastrointestinal nematodes and cestodes in Iraqis. Asian Biomed 2016; 10 (1): 61-66.

59. Curtis V, Cairncross $S$. Effect of washing hands with soap on diarrhoea risk in the community: a systematic review. Lancet Infect Dis 2003; 3:275-81.

60. Arinola $O$, Fawole $O$. Age and sex graded helminth infections in a Nigerian village. East African Med J 1995; 72: 110-112.

61. Schmunis GA, Lopez-Antunano FJ. World-Wide importance of parasites. In: Cox FEG, Wakelin D, Gillespie SH, Despommier DD, editors. Toply and Wilson: Microbiology and microbial infections, 2010; Parasitology. London: Edward Arnold; 2005; p 24. 